\title{
Future Scenarios on Bluetooth: Effects on Value Networks and Business Models
}

\author{
Liisa-Maija Sainio and Taina Sikiö \\ Telecom Business Research Center, Lappeenranta University of Technology, P.O. Box 20, FIN- \\ 53851 LAPPEENRANTA
}

Key words: Bluetooth, value network, business model

\begin{abstract}
The paper presents a study investigating the effects of Bluetooth - a short range wireless technology for Personal Area Networks - on value networks and business models of the players of infocom industry. Bluetooth is examined from a strategic perspective, including its nature as an enabling technology, a value innovation and a potentially discontinuous innovation. The employed methodology has characteristics of futures research and scenarios are used as a basis for group discussions, which are analysed qualitatively. The results indicate that greatest changes will occur in operators' and content providers' value networks and business models.
\end{abstract}

\section{INTRODUCTION}

One of the most promising innovations of the wireless world is Bluetooth, a wireless technology for data transfer, which allows devices such as portable computers, mobile phones and other electronic devices to communicate with each other without the burden of cables, form ad hoc networks and support automatic data synchronization between devices. All the modern innovations in information and communications technologies (ICT) may enable changes in organizational structures and business processes and thus affect the competitive advantage of companies. The market position and traditional business concept of operators is threatened by many factors, as the traditional revenue source of voice traffic becomes a 
bulk product, competition intensifies due to deregulation, and new wireless technologies pose both threats and opportunities for operators. The positions of other players of the information and communications industry are maybe not so directly threatened, gut the general uncertainty of the development affects all players' strategic choices and makes them forced to probe and learn and try to stay atop of technological developments in various fields. As Louis Pasteur said, "chance favours the prepared mind". Therefore, it is beneficial to try to envision the possible changes in value networks and business models in advance. The purpose of this paper is to examine the possible changes in value networks and business models around Bluetooth applications based on group discussions around future scenarios of Bluetooth usage. The characteristics of Bluetooth are first discussed from a strategic perspective, after which the scenarios are presented. Chapters from 3.1 onwards are based on a qualitative analysis of the group discussions.

\subsection{Definition of concepts}

\section{Value network}

Value network, value net and value web are recent, similar concepts that frequently come up in current literature concerning the change from Porterian value chain thinking to more dynamic and complex value network thinking. The supply chain management oriented definition for value net is the following: "A value net is a dynamic network of customer/supplier partnerships and information flows. It is activated by real customer demand and it is capable of responding rapidly and reliably to customer preferences. The players operate within a collaborative, digitally linked network." (Bovel $\&$ Martha 2000, 24) All value networks acquire, create and add value as the customer defines it. (DeRose 1994, 18) The change to value networks has been accelerated by advances in technology (Andrews \& Hahn 1998, 7), which enable direct, real-time communications to multiple parties and solve many problems of coordination. Andrews and Hahn $(1998,8)$ state that the focus in value web is business-goal specific and aims at linking with relevant partners from other industries. The value networks may be roughly divided to two groups: networks of equals and strategic networks. A strategic network has a clear centre, which acts as a brain and a strategist to its partners. (Volberda \& Baden-Fuller 1998, 384-385) In addition, the strategic centre possesses the direct customer contact. The concept of strategic network is valid in the context of this study, since it is relatively more stable and the coordination role of the strategic centre is quite essential for the network to function efficiently. 


\section{Business model}

A business model or a business concept is in the core of business: What is produced and sold, how and to whom? How does the value of the product or service form? What is the earning logic behind profit making? In legal terms, a business model is a general vision or strategy, while business method is a specific way of doing business, and which may in some cases be patented. (Dickinson in Ovans 2000, 16) A narrow view of business model is that it "spells out how a company makes money" (Rappa 2000), that is, the description of the earning logic. A broader, yet precise definition, suitable for the purposes of this paper, is that "a business model is defined as the organization of product, service and information flows, and the sources of revenues and benefits for suppliers and customers" (Timmers 2000, 31).

\section{Scenario analysis}

Scenario analysis offers one way to deal with complexity and uncertainty, and it involves the development of a set of scenarios that describe what the future environment will contain. (Aaker 1988, 121) The goal of scenario analysis is not to predict the future as it will in reality be, because it is not believed to be possible. Instead, the objective is to sketch several different "scripts", scenarios, whose value is not determined by their probability of materialization but on the valuations linked to the paths of events described by scenarios. (Mannermaa 1993, 27) Scenarios may be defined and constructed in various ways; depending on the intended usage.

\subsection{Methodology}

In order to investigate the possible changes Bluetooth might have on operator's value networks and business models, two rounds of group discussions were organized. Group discussions were used because the participants interact with each other and thereby stimulate each other, and the issues brought up may differ from those that would be attained in individual interviews. (Eskola \& Suoranta 1998, 95) The basis of the discussions was a set of three scenarios, each representing a possible value network describing the roles of the players and the position of Bluetooth applications. The discussions were expected to give information on how the roles of the information and communications industry players might change and what the impact of Bluetooth on value networks and business models could be. The participants for group discussions were selected so that they represented different types of industry players, such as telecom operator, terminal provider, software vendor and system integrator, and also general experts on the field. There were 11 participants altogether in the discussions. 
The group discussions were organized during Autumn 2000, and they were a part of a larger qualitative case research investigating the effects of Bluetooth on business models from the perspective of operators.

\section{PRESENTATION OF BLUETOOTH - TECHNOLOGY}

Bluetooth is the official name of a specification for wireless technology that lets devices communicate in near distance with each other by using a secure radio frequency. Bluetooth creates ad hoc wireless networks among just about any devices with the necessary logic. A Bluetooth device itself is a small, low-powered radio on a chip that operates in the $2,45 \mathrm{GHz}$ radio band that is unlicensed and available almost worldwide (Frazier 2000, 43). Bluetooth radio link can transmit through non-metal solid objects and therefore allows data transmission through thin walls and briefcases. As a short-range radio link, Bluetooth operates in all directions and carries from 10 centimeters to 10 meters but it is possible to extend the transmitting range up to 100 meters by increasing the transmit power. (Hill 2000, 16) In addition to easy connectivity with Bluetooth, communication is secure and inexpensive, and happens at a fairly high data transmission rate without lineof-sight requirements, which all are characteristics that make it suitable for multiple situations. (Frazier 2000, 43) Bluetooth can do more than just replace point-to-point cables. It supports point-to-multipoint connections as well, which enables connection of multiple devices into instant, ad hoc networks. Some envision executives in a meeting linking their handheld computers to compare agendas or to exchange virtual business cards or other files. A speaker could also send slides wirelessly to an overhead projector. Another advanced use of Bluetooth-technology would be internet or LAN access point, which you could use just by standing nearby and your cell phone or handheld could log on at a quite respectable speed of $721 \mathrm{kbit} / \mathrm{sec}$. (Deckmyn 2000, 73)

Bluetooth technology has been developed and promoted by Bluetooth Special Interest Group (SIG), which was founded 1998 by Ericsson, Nokia, IBM, Intel and Toshiba corporations. The group has currently about 1900 associate members, who are allowed to use the specification for developing and manufacturing products and software. The purpose of Bluetooth SIG is to promote Bluetooth and ensure that the devices being developed will be compatible with each other. The SIG also sees to that the products allowed to use the trademark comply with the specifications and meet the required qualifications. 
It has been predicted that Bluetooth will roll out in three waves: In the first wave Bluetooth will be attached to high-end cellular phones and through PC cards to notebooks, and it will be offered as an option on some laptops. The first set of Bluetooth products will be targeted for business professionals who use wireless data to increase their productivity. In the second wave, the Bluetooth-enabled device collection will diversify, with the technology serving consumers in everyday situations. The second wave will engulf lower-cost mobile phones and portable devices, digital cameras, printers, automotive systems, home networking and a variety of vertical markets. In the third wave, the technology will be ubiquitous and appear in all kinds of devices to make their use more convenient. (Karlstedt 1999a; Menezes 1999; Ohr 1999b)

\subsection{Benefits of Bluetooth}

Bluetooth enables creation of some new applications and services, but mostly it offers convenience of use to current devices. The use of Bluetoothenabled devices is easier because connections can be formed automatically and wirelessly, and the devices can be used to multiple purposes. Convenience is provided by applications that have such features as automatic personal adjustability, remote control or electronic cash capabilities. Besides convenience, Bluetooth offers also improved efficiency and productivity to business users, resulting to greater accessibility and better responsiveness. (Sainio et al. 2000, 12-15) It enables more convenient access to the Internet and email, and also data transfers between parties in wireless ad hoc networks. Forming of Personal Area Networks (PAN) between personal devices provides better working conditions when on the way.

\subsection{Bluetooth from a strategic perspective}

Bluetooth is by nature an enabling technology, which means that it brings new features into existing devices and may give rise to a multitude of services. Since the product standard is open, producers across the field of telecommunications, information technology and consumer electronics are developing their own applications utilizing the characteristics of Bluetoothtechnology. Bluetooth is a major shift from premise-based to person-based communications (Carrier in Scheiderman 2000, 9), because it enables even greater mobility and access to different services in different platforms. Bluetooth has the potential to change both the way people use mobile devices and future terminal design (Reeves 1999, 30). The technology's greatest synergy is with established wireless-communications products. In 
addition, coupled with WAP or a more developed mobile Internet connection, Bluetooth provides a local link that opens up new e-commerce or mobile-commerce potential. (Bickers 2000, 54) The diffusion of Bluetooth products may be similar to that of standards: there is a snowball or network externalities effect meaning that the greater the number of people using the products the more valuable they become for the users, and therefore the greater the number of people are motivated to use them (Evans and Wurster 1999, 35). In addition, Bluetooth may enable a device, for instance PDA, to make a large-volume commercial breakthrough.

Bluetooth-technology may be considered as a potential value innovation. Kim and Mauborgne $(1999,46)$ define value innovation as something that focuses on redefining the problem the product solves and shifting the performance criteria that matter to customers. Value innovation thus offers customers radically superior value, furthermore with a price accessible to large-volume market. The characteristics of Bluetooth are likely to elevate the performance criteria: when customers get used to wireless products, the traditional solutions will seem obsolete. Visions of Bluetooth-devices have also brought up critique: for instance a Bluetooth smartphone that talks wirelessly to cars and domestic appliances is likely to remain a prototype, unless customer needs concerning the product and access to services are carefully examined. A simple and convenient user interface, strong Webusability and easily customizable operating system will be essential topics prior to a breakthrough in the marketplace (Hughes 2000, 48).

The development of the whole telecommunications sector appears to be quite scattered for the next few years: The third generation wireless and fixed broadband networks will become more common but the global standard does not yet exist. There will be a multitude of devices and services with different characteristics: some devices play music, some show films, some act more as computers and some devices are primarily phones. The combinations of characteristics may differ greatly from today's situation, and only the best will survive on the marketplace. (Mielonen in Leino 2000, 16) The scattered market may actually work for the benefit of the diffusion of Bluetooth products: During the next few years, it will be essential that enterprises and individuals have access to dual-mode handsets and intelligent network links that facilitate the switching between fixed and wireless networks and route voice and data correctly (MultiMedia Telecommunications Association 2000). Bluetooth-products are one answer to this need, since Bluetooth may be a part of both wireless and fixed broadband networks increasing the versatility of devices: the technology makes it easy to move from one network to another, and devices with Bluetooth radio chip talk to each other without the user's initiative. Therefore, Bluetooth increases flexibility and interoperability giving more 
choices for the user. In addition to being an enabling technology, Bluetooth could thus be called a linking technology.

Bluetooth may also be an innovation enabling order-of-magnitude changes in the marketplace, thus considerably affecting the strategic choices of a firm. Such discontinuous innovation may be simply defined as the next killer application or radical innovation (Lambe and Spekman 1997), or as displacing an existing technology paradigm and requiring customer to change (Moore 1991). A more recent term is disruptive technology used by e.g. Bower \& Christensen (1995): Disruptive technologies bring a very different value proposition to the market when compared to choices previously available. Products based on disruptive technologies are typically simpler, smaller and cheaper. (Christensen 2000, xviii, xxix) The definitions of disruptive technology and discontinuous innovation hold different perspectives, and no single definition is yet widely accepted. In general, it may be said that a disruptive technology refers to an indirect substitute for an industry, providing different product-market paradigms, while discontinuous innovations are technologically and/or commercially discontinuous. (Walsh \& Linton 2000, 24) It is not possible to determine exactly ax ante, whether Bluetooth is a discontinuous innovation or a disruptive technology; it is only ex post that an exact determination is possible. However, it is useful to enlighten the characteristics of Bluetooth with the help of such concepts.

\section{BLUETOOTH SCENARIOS}

Scenarios are one possibility to describe simplistically the possible value networks emerging in the marketplace due to Bluetooth products and services. The basis of these scenarios and the idea of three different strategic centers is gotten from Ericsson Ab's internal study dating from 1997. Ericsson $\mathrm{Ab}$ made scenarios concerning the general field of communications of tomorrow. The views of experts were summarized in three scenario models, each having one of the players of the value chain as the leader of development - a so-called strategic center - and others in the role of a subcontractor. Here are the scenarios of Ericsson Ab presented shortly:

1) Up'n Away scenario is led by devices used by consumers. Consumers program their own personal tastes and needs to their devices that can be called "smart clients", and collect the contents and services they need from different networks.

2) Gran Tradizione is a scenario where the company providing network distribution - the operator - is central to the whole process: it buys contents to its portals from content providers and the characteristics of the network affect the device development and consumer tastes and needs. 
3) Service Mania refers to a scenario led by the content provider, for example a media house. It buys the distribution network from teleoperators through bidding and assumes that consumers' devices develop to fit the contents they provide. (Kurki 1999, 9)

The idea of these scenarios was combined with the possible positions of Bluetooth-enabled products and services in the marketplace, resulting to three possible scenarios of Bluetooth usage. The scenarios do not exclude each other, but may co-exist in different applications and market areas. They may also present the sequence of development, scenario 1 being the first phase, and scenario 3 the last. To clarify, Bluetooth product refers to a device containing a Bluetooth chip with the characteristics that Bluetooth then offers. Bluetooth-enabled service, on the other hand, refers to activities that add value to the basic usage of Bluetooth products.

\subsection{Scenario 1: Bluetooth product applications dominate}

Bluetooth is used because of the basic product features: convenience and wirelessness are the benefits for the consumers, and applications such as an electronic wallet, simple game networks or access supervision gain market share. Bluetooth is used in mobile devices and home electronics, more advanced services are inexistent. As the features that Bluetooth provides are quite simple and they are integrated into the terminals, the users see them as product features. Therefore, the few service providers that exist, cooperate with the terminal provider. An operator has a minor role and acts mainly as a bit pipe to transmit data needed in ensuring operations, such as electronic payment. The Bluetooth chip is installed by device manufacturers, who act as strategic centers in the value network, coordinating the operation and having a direct contact to customers. Figure 1 presents the value network for this scenario.

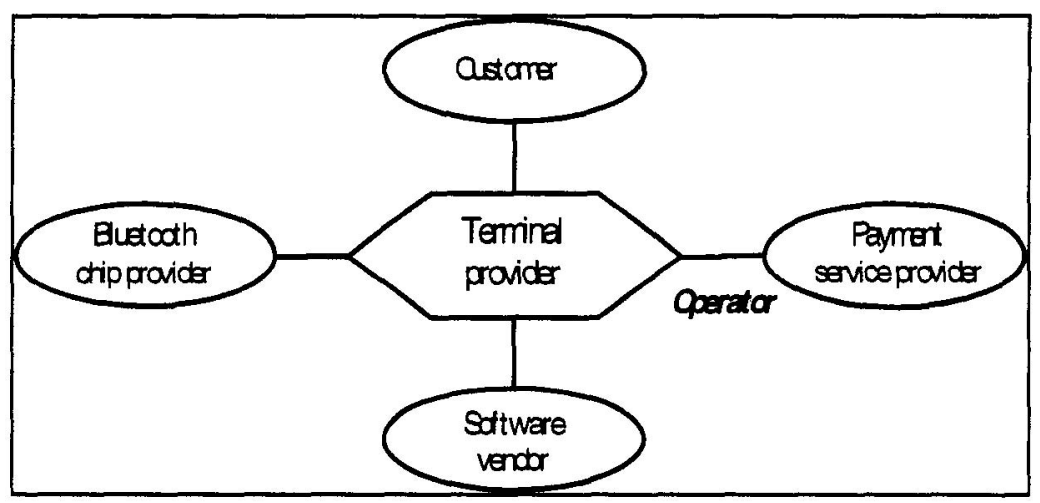

Figure 1. Value network for scenario 1 


\subsection{Scenario 2: Small markets, small service providers}

Bluetooth applications are used mainly because of product characteristics, but also game networks and other services such as pushadvertising and public Internet ports gain market share, while still being niche services targeted at small and specialized user groups. Operators are strategic centers to Bluetooth service provision as shown in Figure 2, because of economies of scale in marketing and distribution and existing customer databases with customer profiles; content and service providers are still small and medium enterprises because of smallness of markets. The operator has direct customer contact and customers' trust. In addition, terminal providers have direct customer contact while selling the terminals. The system integrator and the content aggregator are closely linked to the operator.

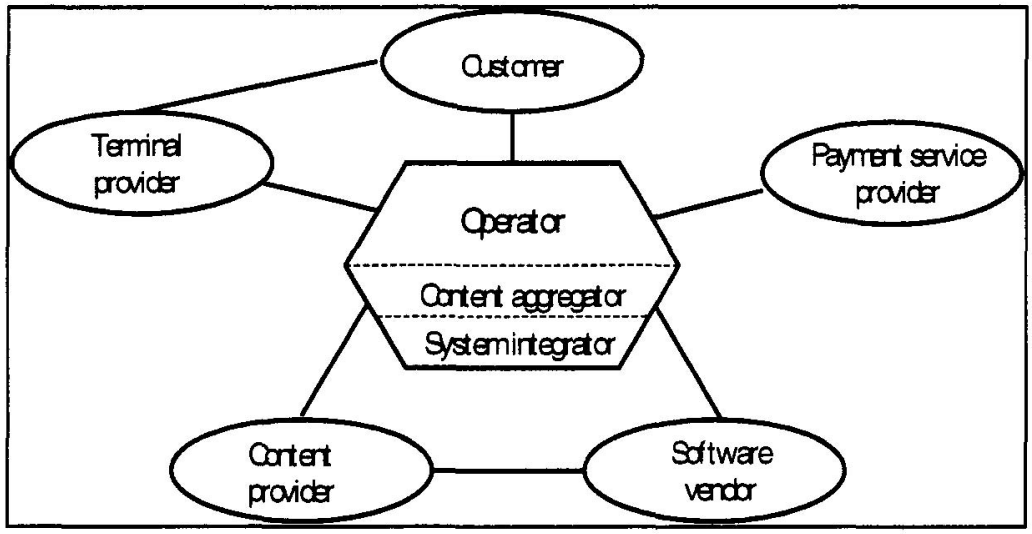

Figure 2. Value network for scenario 2

\subsection{Scenario 3: Bluetooth services for masses}

All kinds of Bluetooth services are used in large volumes, therefore big service providers want to control the service provision. They have grown or consolidated with prior experience of Bluetooth services provided in scenario 2. A service provider may be a media house, a game company or an operator, if operators continue moving into the service provision market. Critical players in addition to strategic centers are portal owners and navigators, who lead the potential customers to services. Service payment vs. free services paid with receiving advertisements are important issues concerning the earning logic. The service scale is wide ranging from general services with large volumes to specialized services to niche groups. The role of operator could also be a customership operator, which would act as a 
customer's trusted agent by keeping confidential customer information, securing the payments and possibly re-aggregating and ranking the services provided by content providers which may also be very local "operators". The value network fror this scenario is presented in Figure 3.

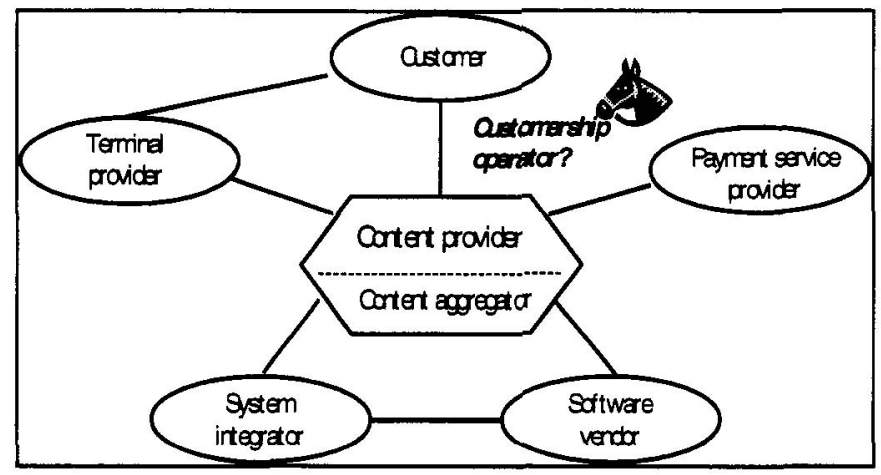

Figure 3. Value network for scenario 3

\subsection{SWOT-analysis of Bluetooth}

This chapter and the following chapters are based on group discussions and analysis of its themes. The basic opinion of the participants of discussions was that Bluetooth is considered to have great potential to become a significant technology but at the same time it is seen as one wireless technology among several others. It is commonly agreed that there is a need for such a technology and if it is not Bluetooth there will definitely be some other technology that will enable similar functions. Bluetooth has many strengths that could make it a dominant standard but also some weaknesses that might annul its significance. The so-called SWOT-analysis consisting of strengths and weaknesses of the technology, and opportunities and threats of the environment, is presented in Figure 4.

Versatility and applicability to multiple purposes are significant strengths of Bluetooth and they may make it superior to competing technologies. The fundamental strength of the technology, convenience of use, may also have extensive implications as it may significantly increase the use of portable as well as fixed network devices in the Personal Area Network. In addition, a significant strength, which may bring considerable opportunities, is that the interoperability has been built in cooperation between several companies. Besides ensuring the interoperability of the devices it helps driving down the costs and diffusing the technology fast to a wide area. The diffusion may also be aided by increased demand for all kinds of portable devices and 
moving to flat rate charging for mobile network usage. Such a discontinuation point that there was with ISDN when it suddenly became popular when homes needed to be supplied with a fast Internet access could seal Bluetooth's success. As Bluetooth may potentially be integrated into almost any kinds of electronic devices, the opportunities in different segments are immense. The increasing networking of companies may also bring opportunities as all the parties need up-to-date information, for example about the logistics processes, which can be monitored with the help of Bluetooth.

\begin{tabular}{|c|c|}
\hline $\begin{array}{l}\text { Strengths } \\
\text { - Convenience of use } \\
\text { - Wider access to networks } \\
\text { - Low power consumption and fast data } \\
\text { transfer } \\
\text { - Applicable to multiple purposes } \\
\text {-Interoperability built among several } \\
\text { manufacturers }\end{array}$ & $\begin{array}{l}\text { Weaknesses } \\
\text { - Standard still in the beta phase } \\
\text {-Complexity of the standard } \\
\text {-Interference problems } \\
\text { - High price (at the moment) } \\
\text {-Quality of Service (QOS) hard to } \\
\text { guarantee } \\
\text { - No existing killer application }\end{array}$ \\
\hline $\begin{array}{l}\text { Opportunities } \\
\text { - Discontinuation point in the market } \\
\text { - Flat rate charge for using mobile } \\
\text { network } \\
\text {-High demand for portable devices using } \\
\text { battery-power } \\
\text { - Growth of the mobile phone market } \\
\text {-Demand for a wide array of segment } \\
\text { specific applications } \\
\text {-Personal Area Network applications } \\
\text { - Networking of companies (up-to-date } \\
\text { information required) }\end{array}$ & $\begin{array}{l}\text { Threats } \\
\text {-Unlicensed frequency band } \rightarrow \text { QoS? } \\
\text {-Poor interoperability of the devices } \\
\text {-Price remains too high } \\
\text {-Devices cannot support the features for } \\
\text { years } \\
\text { - Substituting technologies } \\
\text { - Emergence of a new dominating standard } \\
\text { of wireless data transfer } \\
\text { - Strong standard cannot be created } \\
\text { - Tiring and disappointment of the market } \\
\text { - Applications introduced before fully } \\
\text { operating } \\
\text {-Insufficient capacity of the networks }\end{array}$ \\
\hline
\end{tabular}

Figure 4. SWOT-analysis of Bluetooth

The main concerns that came up in the discussions have to do with the building of and the complexity of the standard, its substitutes and the assurance of the quality of service after the applications are introduced. In history, dominant standards have been built within specific segments, and after one segment has adopted the technology it has expanded to other segments and slowly grown to a general standard. Bluetooth, on the contrary, has no killer application yet and it is seen rather as a universal solution to all problems. It was originally planned to replace cables but at the moment the most of the specification is far from the original purpose. The development of a complex standard may take too long and substituting technologies may establish positions in the market before Bluetooth even properly enters it. There is also a danger that the features that have been 
planned, cannot be supported by the devices for several years and the networks may not be able to handle great numbers of users. If this happens, users who actually want quite simple applications, may become disappointed and find no reason to use these devices. This is a major concern as it may ruin the whole technology, and therefore quality of service needs to be guaranteed by some party. It is also necessary because of the unregulated frequency band that is not coordinated by anyone. Interoperability, at least on the platform and protocol level, is built among several manufacturers and controlled by the Bluetooth SIG, but how the terminals of different providers operate with each other in practice will be very important.

\subsection{Implications on the ICT value network}

The players of the ICT sector, except for device manufacturers who are striving to get products to the market, were in a hold position at the time of the group discussions, waiting for development in markets. Meanwhile, they develop solutions for other technologies and are ready to apply them to Bluetooth once they get some kind of a signal from the market to start acting.

As Bluetooth provides convenience of use to devices and applications, as well as makes the user interface of multiple devices simpler, it is likely to increase the number of users. The increased convenience of interconnecting devices may also change the type of the used devices and the way they are used. As the user base grows, the demand for related services is likely to increase, especially as their use is more convenient with the better devices. (Sikiö 2001, 73) At the same time, content provision becomes easier since basically anyone can deliver content over Bluetooth. Bluetooth may also solve locally or together with the third generation network technologies the existing bottleneck that prevents good content from entering the market because it enables the delivery of larger content over the wider band. All this results in numerous new opportunities for content providers and companies enabling the provision. Since Bluetooth operates in an unregulated frequency band and the standard may be openly used, the opportunities may be exploited by anyone who is willing to develop an application and use the band for data transmission. The openness is likely to induce plenty of companies to develop applications as well as facilitate the expansion of the technology and help improving the standard.

In many situations Bluetooth services can be created and used without any national telecom operator as the data transmission is only local. It is likely that there will appear smaller local operators that either manage their own local communication or that of a number of local actors. Traditional operators are, therefore, likely about to confront competition from new 
directions. It can be expected that the amount of provided content will increase and its nature change as well as the number of actors increase. All this is likely to lead into increased traffic and complexity of the networks and higher need for coordination of the activities. This kind of a model where the market is very fragmented and content is pushed by a great number of providers is hard to manage. Even though the local actors may have extensive customer information, it is unlikely that they are able to manage customer profiles other than basing on local information. The system is even less appropriate for customers, who would need to establish relationships with all the companies providing Bluetooth services that they might be willing to use. Therefore, it is likely that there has to be some actor to manage the customer relationships and guarantee the quality of service to customers as well as manage the cooperation among companies.

\subsubsection{Changes for operator}

The basic function of operators has been voice and data traffic. For that business, Bluetooth poses both threats and opportunities. Bluetooth enables wireless local data transfer, thus making mobile networks locally unnecessary. On the other hand, it offers a more convenient access to networks, which may result in increased traffic in mobile networks. For the service business, Bluetooth offers a possibility to enter the local services market. More likely, however, operators will utilize their competences in coordination and customer relationship management, and build services based on these competences. In addition, customers' trust is an essential element for successful services: operators may act as trusted intermediaries for their customers as they use the services of small local operators. Despite the existing competences, operators should be ready for competition from surprising directions: banks, credit card and insurance companies and supermarket chains have extensive customer databases, and using that data for customer profiling would be a natural extension of their business.

\subsubsection{Changes for terminal provider}

The changes are not very radical in the business of terminal providers. Bluetooth replaces the cord in terminals, and thus makes the devices more attractive, convenient and flexible to customers. Bluetooth may not increase the number of sold terminals, but it certainly adds their usage value. It has to be remembered that terminal providers hold a direct customer contact by selling the devices, which makes them powerful in the value network and the general development: terminal providers make important choices affecting the characteristics of services that can be offered. Bluetooth might favor the 
development of the terminal market towards the usage of multiple specialized devices that are easily interconnected instead of the usage of one multipurpose device. In addition, Bluetooth provides possibilities to develop devices for industry use in logistics and surveillance functions.

\subsubsection{Changes for content providers and content aggregators}

Bluetooth adds a new distribution channel to content providers and gives them more power in the value network. As Bluetooth enables direct local communication, it opens up a new possibility to deliver content without any intermediary and thus lowers the barrier especially for small companies willing to locally communicate with their customers. In addition, besides making the content provision easier, Bluetooth may solve the existing bottleneck of content provision as it offers a wider access to content. It enables the distribution of larger and better content and may thus drive a change in the nature of content. On the other hand, there may be opportunities in providing small, few-bit sized information as well. Frequent use of narrow and inexpensive information may even be more likely than the use of large-sized content especially if the content is accessed via cellular network. New opportunities for content providers may also arise as value creation will increasingly be based on customer profiling and positioning, and Bluetooth may help offering personalized content. As the amount of content grows, it is likely that there will also be considerable opportunities for aggregators that bundle related content to unified appearances and by filtering and refining the immense amount of information add value to it.

\subsubsection{Changes for software vendors and system integrators}

Software vendors and system integrators may expect new opportunities to apply their technologies, even though their roles are not likely to change much. They are usually more or less subcontractors to operators and terminal providers as they enable their applications to work easily and reliably. Therefore, as operators and terminal providers add new products or services to their portfolios, these enabling parties may find growth opportunities as principally all the applications require software and system integration. They are also significantly affected by the decisions of the operators and terminal providers, who can partly control their operations. The success of software vendors and system integrators depends much on the success and the role of their partner. For example, a vendor building software for an operator is likely to benefit the most when the operator is as the strategic center of the value network. For some actors the prevailing value network and its strategic 
center may even affect the channel choice as the dominant actor may be the best and most profitable choice for distribution.

Bluetooth, in general, may give an opportunity to increase production as well as to widen the customer base to emerging new operators or other companies exploiting Bluetooth. For many software vendors and system integrators, however, Bluetooth is one access technology among several others and it mainly affects indirectly as it enables the offering of better and more conveniently usable applications to customers.

\subsection{Effects on business models}

The basic question concerning the possible changes in business models is, whether Bluetooth is seen merely as a wireless technology and a protocol stack that does not change business logic in itself, or as a potentially disruptive technology having the benefits of versatility and applicability to wide areas, when changes in business models of existing players and birth of new players are possible. Bluetooth may enable a new earning logic for content providers with push-advertising; it may also drive towards a usage of prepaid services or flat fee rates for services, when the volumes of services could go up. Changes in business models in larger scale are more likely to happen in content providers' and operators' businesses: Firstly, if content providers see the position of strategic center relevant to them, like in scenario 3, that will imply that they must acquire new competences for marketing and distribution. Actually, the participants of the group discussions saw it unlikely that the content providers would have the required competences for being a strategic center. It is clear that it would not be simple. Secondly, if Bluetooth services reach the market, operators have to consider carefully their options. The role of customership operator would be a change in their business model, giving more weight on the service business. One possible new player in the value network would be a local operator, whose business idea might be to provide free local services together with personalized push-advertising.

\section{CONCLUSIONS}

Bluetooth may become one case example of how a potentially disruptive technology may transform business models. The roles of current players in the field of telecommunications - infrastructure providers, device manufacturers, software developers, content providers and service providers - may change: the field will most probably see both vertical integration up or down the current value chain, concentration on more focused activities or the 
rise of new players acting as integrators or navigators. Analyzing and anticipating these new business models is a challenging task for research. Bluetooth as a technology is certainly intriguing with its characteristics and considerable business potential, and future will show which part the development of the whole field of wireless communications will take and what will be the role of Bluetooth in this development.

\section{REFERENCES}

[1] Aaker, David A. (1988), Strategic Market Management, John Wiley \& Sons, Second Edition, New York

[2] Andrews, Philip P. \& Hahn, Jerome (1998), Transforming Supply Chains into Value Webs, Strategy \& Leadership, Vol. 26, Iss.3

[3] Bickers, Charles (2000), Cutting Loose: Bluetooth Technology Promises to Make Obsolete the Wires that Connect many Electronic Devices, Far Eastern Economic Review, March 16

[4] Bovel, David \& Martha, Joseph (2000), From Supply Chain to Value Net, Journal of Business Strategy, July/August

[5] Bower, Joseph \& Christensen, Clayton (1993, Disruptive Technologies: Catching the Wave, Harvard Business Review, Vol. 73 No.1

[6] Christensen, Clayton M. (2000), The Innovator's Dilemma, HarperBusiness, Harvard Business School Press, Boston, Massachusetts

[7] Deckmyn, Dominique (2000), Bluetooth, Computerworld, June 12

[8] De Rose, Louis J. (1994) The Value Network: Integrating the Five Critical Processes that Create Customer Satisfaction, AMACOM, a division of American Management Association, New York

[9] Dickinson, Todd in Ovans, Andrea (2000), Can You Patent Your Business Model? Harvard Business Review, July/August

[10] Eskola, Jan \& Suoranta, Juha (1998), Johdatus laadulliseen tutkimukseen, Vastapaino, Tampere

[11] Evans, Philip \& Wurster, Thomas S. (1999). Blown to Bits: How the New Economics of Information Transforms Strategy, Harvard Business School Press, Boston

[12] Frazier, Robert (2000). Bluetooth a Boon for Wireless Devices, Network World, Vol. 17, Iss. 16

[13] Hill, Julie (2000), Bluetooth Takes its First Bite, Presentations, Vol. 14, Iss. 2

[14] Hughes, Steven (2000), No Need for Smartphones, just Smart Applications, Telecommunications, Dedham, January

[15] Karlstedt, Anneli (1999), The Invisible Connection - Bluetooth, Sonera Reaching Out, 3/1999, Available World Wide Web: http://www.sonera.fi/ english/reachingout/oct99/bluetooth/index.html, Accessed 28.8.2000

[16] Kim, W Chan, Mauborgne, Renee (1999), Strategy, Value Innovation and the Knowledge Economy, Sloan Management Review, Vol. 40, No 3, Cambridge, Spring

[17] Kurki, Markku (1999), Sisältötuotantoa tukevat verkkopalvelut - tarpeet ja mahdollisuudet, TEKES Teknologiakatsaus 73/99, Helsinki

[18] Lambe, C. Jay \& Spekman, Robert E. (1997). Alliances, External Technology Acquisition, and Discontinuous Technological Change, Journal of Product Innovation Management, Vol. 14, No 2 
[19] Leino, Raili (2000), Maailma kuuntelee, mitä Suomen telemies puhuu, Interview of Jari Mielonen, Technology Director of Sonera Oyj., Tekniikka\&Talous, 10.8.2000

[20] Mannermaa, Mika (1993), Tulevaisuudentutkimus tieteellisenä tutkimusalana in Matti Vapaavuori (ed.), Miten tutkimme tulevaisuutta?, Acta Futura Fennica No 5, Painatuskeskus Oy, Helsinki

[21] Menezes, Joaquim (1999), Bluetooth Spec "Kils the Cord", Computing Canada. Vol. 25, Iss. 42

[22] Moore. Geoffrey (1991) Crossing the Chasm, Harper Business Press MultiMedia Telecommunications Association (2000), Wireless Technology creates foundation for future enterprise mobility, Draft of MMTA White Paper, Available World Wide Web: www.mmta.org/research /framel .htm, Accessed 4.7.2000

[23] Ohr, Stephan (1999), Bluetooth Backers Gear up Product Push, Electronic Engineering Times, Manhasset, December 13

[24] Rappa, Michael (2000). Business Models on the Web, Available World Wide Web: http://ecommerce.ncsu.edu/topics/models/models.html,Accessed 10.12.2000

[25] Reeves, Betsy (1999), Phones of the future, Wireless Review, March 15

[26] Scheiderman, Ron (2000), Interoperability tops Bluetooth vendor issues, Wireless Systems Design, Vo1.5 Iss. 1

[27] Sainio, Liisa-Maija, Sikiö, Taina \& Niiranen, Jukka (2000), Application Visions and Business Opportunities of Bluetooth - A Wireless Technology for Local Data Transfer, Telecom Business Research Center, Lappeenranta University of Technology. Working Papers 5, Lappeenranta

[28] Sikiö, Taina (2001), The Role of Bluetooth Technology in Transforming the Value Network of ICT Industry, Master's Thesis, Lappeenranta University of Technology

[29] Timmers, Paul (2000), Electronic Commerce: Strategies and Models for Business-toBusiness Trading, John Wiley \& Sons Ltd, West Sussex, England, Reprint

[30] Volberda, Henk W. \& Baden-Fuller, Charles (1998), Strategic Renewal and Competence Building: Four Dynamic Mechanisms in Hamel, Gary, Prahalad, C.K., Thomas, Howard \& O'Neal, Don (eds.), Strategic flexibility: Managing in a turbulent environment, John Wiley \& Sons, Chichester

[31] Walsh, Steven T. \& Linton, Jonathan D. (2000), Infrastructure for Emergent Industries Based on Discontinuous Innovations, Engineering Management Journal, Vol. 12 No.2 